Peter J. Hosie, Peter P. Sevastos*

\title{
A Framework for Conceiving of Job-related Affective Wellbeing ${ }^{* *}$
}

Beginning with the nature of happiness, the philosophical roots of job-related affect are explored to inform contemporary understandings of the phenomenon. Various disciplines, theories, models and schools of thought are contextualised and related to job-related affective wellbeing. Seminal constructs of affective wellbeing are identified, along with issues involved in developing an integrated model of affective wellbeing in the workplace. A synthesis of the literature is given using a tripartite heuristic framework comprising categories of Dispositional, Activity and Telic. Each category explains the tenets of the most influential theories and debates their veracity. Finally, the key theoretical developments are integrated to provide linkages between the conceptual bases of these constructs.

Key words: job, affective wellbeing, intrinsic job satisfaction, dispositional, activity, telic

* Dr Peter J. Hosie, Associate Professor in Management, Faculty of Business and Management, Block 15, Knowledge Village, P.O. Box 20183, University of Wollongong in Dubai, Dubai, United Arab Emirates. E-mail: PeterHosie@uowdubai.ac.ae.

Dr Peter P. Sevastos, retired Lecturer, School of Psychology, Curtin University of Technology, Western Australia, Australia.

** Article received: April 4, 2009

Revised version accepted after double blind review: April 15, 2010. 


\section{Introduction}

The article provides a comprehensive framework for conceiving of job-related affective wellbeing (affective wellbeing). We begin by exploring the nature of 'happiness' and the philosophical roots of affective wellbeing in the workplace. A theoretical review of the affective wellbeing concepts inform several models that explain this phenomenon. Various disciplines, theories, models and schools of thought are detailed which contextualise affective wellbeing in the workplace. A tripartite heuristic framework comprising: Dispositional, Activity and Telic categories are used to synthesise the literature. Each category of the framework explains the tenets of the most influential theories and debates their veracity. Key theoretical developments are integrated to provide linkages between the conceptual bases of these constructs. Models of affective wellbeing are identified, and issues involved in developing an integrated model of affective wellbeing are given.

\section{Happiness}

Striving toward pleasure or happiness is the basic motivation for all human behaviour (Tracey 1993: 73).

Happiness is arguably fundamental to the human condition, and is the natural state for a human being (Domeyko 1996). Some contend that “... the secret of happiness is the holy grail of the new millennium" (Bagnall 2004). Psychologists now recognise the critical influence of affect in human experience. Affective wellbeing has its philosophical and theoretical foundations in the concept of happiness, one of the most obscure expressions in the English language (Haybron 2003). The word happy is "... characterised by or indicative of pleasure, content, or gladness" (Delbridge et al. 1996: 801). Classical philosophers have contemplated the authentic nature of happiness for centuries. To this day, numerous journal articles and books continue to pursue this most fundamental and elusive of human meaning.

The Greek philosopher Epicurus proffered a hedonistic perspective of happiness which he reasoned to be a natural condition "... guided by our innate instincts for pleasure and penchant for avoiding pain" (cited in Waterfield 1993: 11). According to the ancient philosophers, humankind is destined never to attain happiness, as only the Gods are permitted to recognise the sensation or experience this feeling. As with beauty, Plato reasoned that happiness cannot be described, but only experienced. Aristotle, an early proponent of 'activity theory', maintained that happiness is achieved through well performed virtuous activity. In the Categoria, Aristotle (cited in Ackrill 1963) approached the concept of happiness in a more temperate way, as one of the eight metaphysical dimensions of life that humans are destined to struggle to attain.

This type of flourishing described by the philosophers Aristotle and Plato was called eudemonia ('having a good guardian spirit'), a valuable kind of wellbeing that is more than a state of mind (Haybron 2003). Aristotle proposed that the pursuit of happiness is the ultimate human undertaking; "... something final and self-sufficient, and is the end of action" (Aristotle 1952). He concluded: "Therefore, we call final 
without qualification that which is always desirable in itself and never for the sake of something else. Such a thing is happiness, above all else, is held to be; for this we choose always for itself and never for the sake of something else".

In a similar vein, Pascal asserted that "... man wishes to be happy, and only wishes to be happy, and cannot wish not to be so" (Pascal cited in Hutchins 1952: 203). More recently, Existentialists argued that humankind is forced to choose between freedom and happiness, because they cannot both be experienced simultaneously (Adolphs et al. 1995). Debate continues amongst psychologists over whether happiness is a state, a fleeting occurrence due to some positive event, or simply the accumulation over time of individual happy feelings. Veenhoven (1995a 1995b) reasoned that happy people are those most able to control their environment.

According to Domeyko (1996: 10) a contemporary metaphysical perspective as to what constitutes happiness is, “... essentially an energy flow that occurs when you remove the negativities and blocks from your mind and so open yourself to more of the life force". Thus, a clear sense of direction seems to be an important aspect of making a valuable contribution to life through "... the progressive realization of a worthy ideal" (Frankl, cited in Tracey 1993: 29). This immutable “... striving toward pleasure or happiness is the basic motivation for all human behaviour" (Tracey 1993: 73). More globally, the Dalai Lama (1999: 62, 263) concluded, “... the purpose of life is happiness", and that:

Ultimate happiness depends on eliminating our negative behaviours and mental states things like anger, hatred, greed, and so on, since excessive levels of worry and anxiety serve no useful purpose and do nothing but undermine ... happiness and interfere with [the] ability to accomplish goals.

Defining the fundamental nature of happiness and measuring its essence is bound to be difficult, as Damasio (1994: 146f.) argued that "[ $\mathrm{t}]$ he essence of sadness or happiness is the combined perception of certain body states with whatever thoughts they are juxtaposed to, complemented by a modification in the style and efficiency of the thought process".

Paradoxically our experience of happiness must also include a measure of darkness; as its opposing force loses its meaning if not balanced by sadness (Jung 1933). Marcel Proust believed that "[h]appiness serves hardly any other purpose than to make unhappiness possible" in conjunction with Mark Twain, who in 1909 observed that “... happiness ain't a thing in itself - it's only a contrast with something that ain't pleasant". From this perspective, happiness is essentially a feeling, a state of mind that is an individualistic experience, since "... what brings happiness to one person ill fits another" (Epicurus, cited in Waterfield 1993: 9). Reasoning and research into the construct of happiness preceded research into affective wellbeing. Emotions and happiness are arguably the 'primitive' (or first order) conceptual bases of affective wellbeing. While emotions and happiness are closely related, they are not identical to the affective wellbeing construct.

Although some ambiguity remains as to whether happiness is an emotion (i.e. joy), a cognitive evaluation (i.e. satisfaction), or a combination of both (Argyle/Martin 1991), the majority of studies have treated 'happiness' as an emotional state. Happiness is related to emotional states like hopefulness, optimism and contentment. The 
empirical nature of contemporary definitions of happiness (many have lamented the atheoretical nature of research in the area) originated in work by Bradburn's and colleagues (1969). Job-related affective wellbeing is the currently the closest available expression of happiness in the workplace.

\section{Emotions and affect}

Emotions are arguably the fundamental drivers of human endeavour (Tracey 1993). People's emotions have a critical role in thought, decision making and individual success. There are substantial differences between emotions, affect and mood. According to George and Brief (1996: 145) affect is “... a broad generic term that covers both the intense feelings and reactions people have, which are commonly referred to as emotions, and the less intense, but no less important, feelings often called moods". Thus, emotions are of short duration, while affect or moods persist over a longer period of time.

Employees who are happy would be expected to display these rather stable characteristics over time. Because emotion or affect encompasses a broad class of events that fall into a single scientific category, Russell and Feldman Barrett (1999) offered an illustration to differentiate emotion from affect or mood. They made an important distinction between prototypical emotional episodes and core affect to draw attention to the practice of using qualitatively different kinds of events to describe the more generic term emotion. A prototypical emotional episode is described by Russell and Feldman Barrett (1999: 806) “... as a complex set of interrelated sub events concerned with a specific object ... that the emotional episode is about". We are, for example, fearful of, surprised at, or angry with someone or about something.

On the other hand, core affect, was referred to by Russell and Feldman Barrett (1999: 806) as “ $\ldots$ the most elementary consciously accessible affective feeling (and their neurophysiological counterparts) that need not be directed at anything ... and can be free floating as in moods". Although core affect and prototypical emotional episodes are related, they are distinguishable, with core effect forming part of a prototypical emotional episode. Core effect can be described in terms of two orthogonal dimensions - the degree of pleasantness and the degree of activation.

A combination of these two independent dimensions provides a descriptive map that can be used to collate core affect at any particular point in time. Russell (1980) argued that affect descriptors in this map are organised in a circular arrangement forming an affect circumplex, where affects at a $90^{\circ}$ angle are independent of each other (e.g., elated vs stressed), while those $180^{\circ}$ apart are semantic opposites (e.g., tense vs relaxed), as illustrated in figure 1 represents the affective space in wellbeing research by integrating Russell's (1980) and Russell and Feldman-Barrett's (1999), Warr's (1990a, 1994c), and Watson's and Tellegen's (1985) conceptualisations of affect.

Although the even spacing of the affect descriptors around the circumference is not a necessary condition for the model, the requirement that the affects are equidistant from the centre of the circle is essential (Russell/Feldman Barrett 1999). This leads to a need to differentiate the various forms of affective wellbeing in the workplace. 
Figure 1: Principal axes of affective wellbeing space (Source: Sevastos 1996: 12)

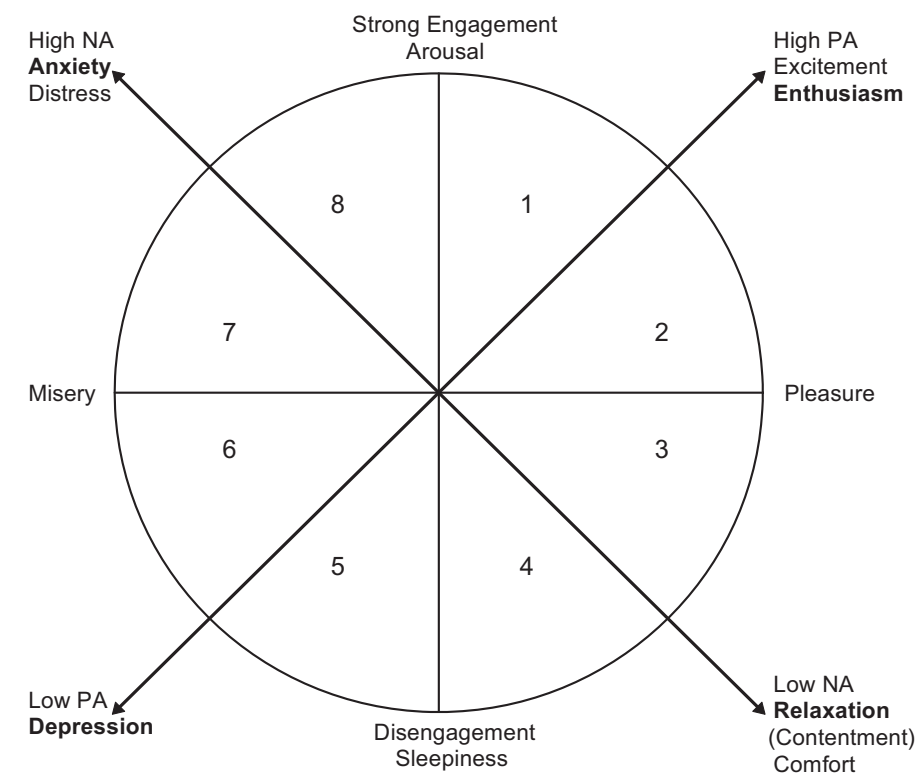

\section{Differentiating forms of affective wellbeing}

Affective wellbeing (Warr 1990b) refers to feelings about either life in general (i.e. 'context-free'), or affect in relation to a specific domain (i.e. 'job-related' and 'facetspecific'). In relation to affective wellbeing, the term 'job' refers to the specific tasks undertaken by individuals in a particular setting, whereas work refers to jobs in general (Warr/Cook/Wall 1979: 1179). Table 1 and figure 2 illustrate how aspects of jobrelated, context-free and facet-specific affective wellbeing relate to the affect axes of Discontented-Contented, Anxious-Relaxed and Depressed-Actively Pleased. Table 1 provides details of the differences between job-related, facet-specific and context-free affective wellbeing.

Table 1: Affective wellbeing axes of measurement and levels of specificity (Source: Warr 1987: 47)

\begin{tabular}{|c|c|c|c|}
\hline \multicolumn{4}{|c|}{ Affective wellbeing } \\
\hline Bipolar Axes & Context-free & Job-related & Facet-specific \\
\hline $\begin{array}{l}\text { Discontented- } \\
\text { Contented }\end{array}$ & $\begin{array}{l}\text { Happiness } \\
\text { Life satisfaction } \\
\text { General distress } \\
\text { Negative affect }\end{array}$ & $\begin{array}{l}\text { Job satisfaction } \\
\text { Job attachment } \\
\text { Organisational commitment } \\
\text { Alienation from work }\end{array}$ & $\begin{array}{l}\text { Specific satisfaction (with } \\
\text { pay, amount of responsi- } \\
\text { bility, etc) }\end{array}$ \\
\hline $\begin{array}{l}\text { Anxious- } \\
\text { Comfortable }\end{array}$ & $\begin{array}{l}\text { Anxiety } \\
\text { Neuroticism }\end{array}$ & $\begin{array}{l}\text { Job-related tension } \\
\text { Job-related pressure } \\
\text { Resigned satisfaction }\end{array}$ & $\begin{array}{l}\text { Specific feelings of job } \\
\text { strain }\end{array}$ \\
\hline $\begin{array}{l}\text { Depressed-Actively } \\
\text { Pleased }\end{array}$ & $\begin{array}{l}\text { Positive affect } \\
\text { Depression } \\
\text { Tedium } \\
\text { Self-denigration }\end{array}$ & $\begin{array}{l}\text { High morale } \\
\text { Job involvement } \\
\text { Job boredom } \\
\text { Job-related depression } \\
\text { Job-related burnout }\end{array}$ & $\begin{array}{l}\text { Specific aspects of job } \\
\text { boredom, and learned } \\
\text { helplessness }\end{array}$ \\
\hline
\end{tabular}


A host of context-free and facet-specific factors impact on affective wellbeing. Differences between job-related, facet-specific and context-free affective wellbeing are schematically represented in figure 2 .

Figure 2: Differentiating job-related affective wellbeing from facet-specific and context-free affective wellbeing (Source: Hosie/Sevastos/Cooper 2006)

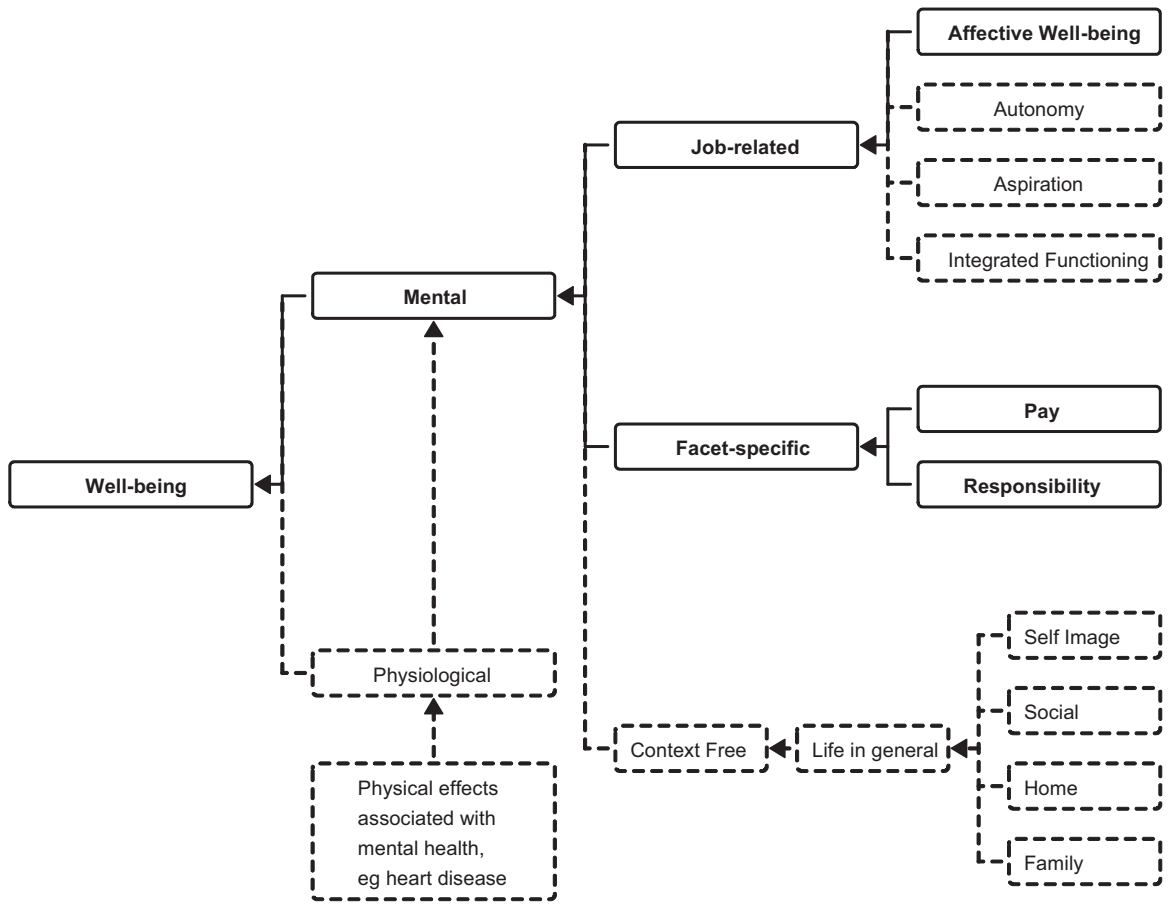

Context-free and facet-specific affective wellbeing have different predictors. Facetspecific affective wellbeing includes factors such as pay, responsibility, colleagues, supervisors, working conditions, promotional prospects, and security of employment, the organisation as a whole, and the kind of work undertaken. Context-free affective wellbeing includes factors such as satisfaction with self image, physical health, and social and home life which are known to contribute to affective wellbeing, but are outside the scope of the this investigation (Warr 1987). Although there is ample research evidence of interactions between employees' work and their life in general, these have not been included as they have already been thoroughly dealt with in other studies (e.g., Cooper 1996; Warr 1990a).

In Bradburn's terms, happiness has been operationalised as the balance between positive and negative affect. There is now a large body of research confirming Bradburn's results. When these ratings of adjectives describing affects were factor analysed, two dimensions usually account for the major portion of variance. The usual finding from the unrotated solution has been a pleasantness-unpleasantness dimension defined by such terms as satisfied, pleased vs. unhappy, sad, and an activation or arousal dimension defined by aroused, surprised vs. still, quiet, and so forth (Russell 1980). 
Watson and Tellegen (1985: 220) concluded that “... in our own studies and in virtually all published self-report studies that we have subsequently reanalysed, we have encountered the same two large, bipolar dimensions". A two factor structure of affect emerged, labelled Positive Affect (PA) and Negative Affect (NA) by Watson and Tellegen (1985).

\section{Positive and Negative Affect}

Consistent with this conceptualisation is Warr's (1990a, 1994c) description of affective wellbeing in the occupational setting through two principal axes, are labelled anxietycomfort (high and low NA respectively) and depression-enthusiasm (low and high PA respectively). These two axes parallel those of Watson and colleagues, and are measured through scales that capture similar affects to those captured by Brief, Burke, George, Robinson, and Webster (1988). These dimensions have been re labelled nervousness-relaxation, and enthusiasm-fatigue by Burke, Brief, George, Roberson and Webster (1989).

Diener and Emmons (1985), however, have proposed a somewhat different affect structure from the one proposed by Watson and his colleagues. Diener and Emmons used PA items such as happy, pleased, and satisfied, while NA was defined by unhappy, blue, and lonely, etc. PA, therefore, captures the 'pleasantness' sector of Watson and Tellegen's (1985) affective space (shown in figure 2, sectors 2 and 3), and NA captures the 'unpleasantness' and 'high negative affect' space (sectors 6, 7 and part of sector 8). According to Watson (1988) this definition is the opposite of high PA (enthusiastic, elated, etc.) is low PA (sluggish, sleepy, etc.), while the opposite of high NA (hostile, scornful, etc.) is low NA (calm, relaxed, etc.).

In this bipolar conceptualisation of affect only the high poles represent the experience of affect per se, while the low poles represent states that are relatively free of emotional involvement. Other researchers have proposed similar affective structures, albeit using different labels to explain the equivalent constructs. For example, Watson's (1988) high PA is Thayer's (1978) 'high energetic arousal', and Mackay, Cox, Burrows and Lazzarini's (1978) 'high arousal'. Thus, Watson's low PA is Thayer's 'low energetic arousal' and Mackay's et al. 'low arousal'. Also, Watson's high NA is Thayer's 'high tense arousal' and Mackay's et al. 'high stress', while Watson's low NA is Thayer's 'low tense arousal' and Mackay's et al. 'low stress'.

An issue that has emerged from research on affect is whether it is useful to distinguish between the frequency and intensity of affective reactions. The distinction is important, because the popular view would suggest that wellbeing is at its maximum when PA is both frequent and intense, while NA is infrequent and in low intensity (Diener/Sandvik/Pavot 1991b). A number of studies were carried out to test this common sense view. Diener, Larsen, Levine and Emmons (1985) reported research suggesting that PA and NA are strongly inversely correlated. Further, work on subjective wellbeing indicated that over time, PA and NA were independent across persons.

To reconcile this inconsistency, Diener et al. (1985) proposed a two dimensional affective structure: the frequency of PA vs NA, and the intensity of affect. Across three studies designed to explore this inconsistency they found that the frequency and intensity of affect varied independently. Although average levels of PA and NA 
showed low correlations, this relationship became strongly inverse when intensity was partialled out. In this way, the intensity dimension helped explain the relative independence of PA and NA.

Diener, Sandvik and Pavot (1991b) also addressed the question whether frequency of PA, intensity of PA, or both are necessary and sufficient for happiness. Their results suggested that happiness or affective wellbeing is related primarily to the frequency and not to the intensity of PA. But why do intense positive experiences (although desirable at the time of experience) not contribute greatly to subjective wellbeing in the long run? This question was answered by Diener, Colvin, Pavot, and Allman (1991a) who in a series of five studies concluded that intense positive experiences may sometimes have costs in the form of increased NA, and lowered positive valence in the face of other good experiences. These costs counterbalance the desirable nature of intense PA. Diener, Sandvik and Pavot (1991b) concluded that it is the frequency of PA that is the "... essence of a phenomenon which can be labelled "happiness".

This chance finding emanating from a study of social change was counterintuitive, because it meant that people who reported high PA were neither more nor less likely than others to report high NA. Up to that time it had been assumed that experiencing one type of affect (either positive or negative) would act against experiencing the other. These two dimensions were also found to be related differentially to sets of variables. For example, PA was related to active participation in social activities, while NA was found to be associated with anxiety, marital and sexual problems, and symptoms of ill health. PA was found to be related to active participation in social activities, and NA was associated with anxiety and symptoms of ill health. Thus, a differential relationship was established between these two dimensions, a finding that overturned the prevailing assumption that experiencing either PA or NA mitigate against experiencing the other.

At this point a distinction should be made between state and trait NA and PA. Measures of current or state affect assess how a person is feeling 'right now', 'today', or 'this week'. However, when instructions are given asking respondents to indicate how they have felt over longer time periods (i.e. over the past few weeks, past few months, etc.) the retest reliabilities of subjects' affect ratings tend to increase as the rated time frame increases. This stability prompted some to suggest that these affect measures may in fact be tapping traits (Meyer/Shack 1989). Depending on the timeframe instructions, these dimensions may also be measured as state or trait PA and NA. State affect represents a person's mood, while trait PA and NA represent enduring aspects of a person's personality. NA and PA. From this it may be possible to establish whether or not affective wellbeing is acquired through changing behaviours. This has important implications for employee practice.

But what do state and trait PA and NA represent? George (1992: 194) has suggested "... that a given state captures the interaction of the relevant personality or dispositional and situational factors". State affect is, therefore, a function of the person and the situation. On the other hand trait PA and NA reflect individual differences in positive and negative emotionality (also referred to in the literature as positive and negative affectivity) that are maintained under all conditions, even in the absence of external stimuli. High NA individuals are, therefore, more likely to report distress, 
discomfort, and dissatisfaction over time regardless of the situation (Watson/Pennebaker 1989), whereas high PA individuals have a sense of excitement and enthusiasm (Watson/Pennebaker/Folger 1987), a generalised sense of wellbeing, and a zest for life, independent of the influences of NA (Costa/McCrae 1980).

Watson (1988) argued that, because these terms are part of the pleasantness and unpleasantness dimensions, they will produce NA and PA factors that are negatively correlated with each other. Sevastos (1996) argued that PA and NA are neither bipolar nor orthogonal but correlated and distinguishable affects. More recently, Feldman Barrett and Russell (1998) recommended using mood descriptors to test the bipolarity versus independence of affect by selecting affect adjectives that were $180^{\circ}$ apart in the affect circumplex (see figure 1), and were opposite in both the arousal and valence dimensions.

The circumplex model may assist in the identification of such semantic opposites, as the affect descriptors are arranged in a continuous fashion around the perimeter of the affective space defined by the orthogonal dimensions of arousal and pleasure (Russell 1980). However, Haslam (1995a 1995b) argued for a simple structure where the circumplex may be better represented by a number of category boundaries that identify discrete segments of the affective space, with low levels of discriminability within segments and stronger levels in adjacent segments, analogous to the colour spectrum. Thus, PA is not simply the opposite of NA but represents a distinct dimension of personality, as Watson, Clark and Carey (1988: 1062) explained:

Positive Affect (PA) reflects the extent to which a person feels enthusiastic, active and alert. High PA is a state of high energy, full concentration and pleasurable engagement, whereas low PA is characterized by sadness and lethargy. In contrast, Negative Affect is a general dimension of subjective distress and unpleasurable engagement that subsumes a variety of adverse mood states, including anger, contempt, disgust, guilt, fear, and nervousness, with low NA being a state of calmness and serenity.

Trait PA and NA are also reflected in individual differences that are maintained by people under all conditions, even in the absence of external stimuli. Consequently, low NA people are more likely to report distress, discomfort, and dissatisfaction over time, regardless of the situation (Watson/Pennebaker 1989). By contrast, high PA individuals possess a sense of exuberance and enthusiasm (Watson et al. 1987), a generalised sense of affective wellbeing, and a zest for life independent of the situation (Costa/ McCrae 1980).

\section{Summary}

Other researchers have also argued for the organisation of affect in a bivariate space. Diener and Iran-Nejad (1986) observed that people rarely experience intense pleasure or displeasure, but are more likely to report mixed feelings at low to moderate levels of intensity. Schimmack (2001), for example, provided evidence to support the coexistence of a model of reciprocally activated affect. He concluded that pleasure and displeasure are best represented by two distinct feelings, or monopolar dimensions that are sometimes experienced concurrently as mixed feelings. The observation that people may experience mixed feelings concurrently is not new and Schimmack, for example, cites McDougal (1905) who remarked more than a 100 years ago: 
It is, I think, indisputable that a man may be unhappy while he actually experiences pleasure, and that he might make it more difficult to find pleasure and might make his pleasure thin in quality, but the two modes of experience, are though antagonistic, not absolutely incompatible and mutually exclusive.

A test on bipolarity versus independence model of affective wellbeing was undertaken by Sevastos (1996). Discrete affects (enthusiasm, depression, anxiety and relaxation) were found to fit the data significantly better than a two dimensional bipolar model (Enthusiasm-Depression and Anxiety-Comfort) proposed by Warr (1990a). The appropriateness of using the four monopolar model (Sevastos 1996) is based on the evidence presented earlier, that affects are organised in a bivariate space, and employees affective feelings of different hedonic tone coexist within a context of daily hassles and uplifts (Kanner et al. 1981) that has become the norm in such occupations.

The notion of happiness is related to affective wellbeing categories. Costa and McCrae (1980: 1062) even proposed a 'model of happiness', asserting that differences among individuals in PA and NA are a direct consequence of differences in the personality variables of extraversion and neuroticism.

\section{Typologies of affective wellbeing}

As noted earlier, affective wellbeing may be categorised into three general clusters of theories; Dispositional, Activity and Telic (Diener 1984). These theoretical typologies were derived from the occupational and organisational psychology literature and provide a useful theoretical framework for conceiving of theories about affective wellbeing. Each typology makes predictions that explain affective wellbeing and the models represent well conceived and thoroughly investigated conceptualisations of affective wellbeing.

\section{Dispositional theories}

There is considerable debate taking place among psychologists on the nature of happiness or wellbeing. The question being asked is whether happiness is a state - simply the accumulation of individual happy feelings - or the predisposition to react in a happy way (Diener 1984). The dispositional approach to affect can be traced back to the writings of Münsterberg (1913: 27) who described the goal of applied psychology as "... the selection of those personalities which by their mental qualities are especially fit for a particular kind of economic work". Ledford (1999: 30) defined disposition as an "... enduring personal attribute". Trait affect is more closely equated with the notion of disposition described by Wright and Staw (1999b; 1999a), and may be described as a constellation of inherited and enduring behaviours that in some instances, may be modified over long periods of time (Ledford 1999). Dispositional theories treat affective wellbeing as an integral part of a person's makeup, whereas situational factors are only considered to contribute a small amount of variance to a person's affective wellbeing.

Lewinsohn and Amenson (1978) contend that a lack of pleasant events leads to depression. In contrast, dispositional theorists argue that depression prevents an individual from feeling pleasure in circumstances that are normally pleasant (Sweeney/ Schaeffer/Golin 1982). Great proponents of the dispositional approach are Costa and McCrae (1980). Costa and McCrae asserted that differences among individuals in PA 
and NA over time are a direct result of differences in extroversion and neuroticism, respectively. This view was strengthened by the research of Meyer and Shack (1989) to examine the degree of convergence between the two dimensional model of affect and personality structure. Extroversion and PA was consistently found to share a common dimension in the combined affect and personality space, while neuroticism and NA together defined the second dimension of this space. This finding persisted whether affect was evaluated as a state or a trait.

Findings showing convergence of affect and personality structure were reported by a host of other researchers (see for example, Brown/Mitchell 1993; Costa/McCrae 1987; Emmons/Diener 1985; Larsen/Ketelaar 1989; Meyer et al. 1989; Watson/ Clark,1984; Williams/Podsakoff 1989). Costa and McCrae (1987) concluded that “... over time, the small but persistent effects of traits emerge as a systematic source of variation in happiness, whereas situational determinants that vary more or less randomly tend to cancel each other out". Research on this 'systematic source of variation' was carried out with trait NA as a control variable examining the relationships between self report stressors and self report strain outcomes. Brief et al. (1988), and Cooper and Payne (Cooper/Payne 1988) established that when the stressor-strain relationship was attenuated, trait NA or neuroticism was controlled.

Work by Schaubroeck, Ganster and Fox (1992) showed that, although NA did not share a common factor space with measures of subjective strain, it attenuated the effects of self report work stressors. These findings, however, are in disagreement with those of Chen and Spector (1991) who found little evidence of attenuation when they partialled NA and trait anxiety respectively from correlations between self report of work stressors and self report strain outcomes. More consistent results have been reported, however, when the examination focuses on trait PA. Studies by Schaubroeck and colleagues found little evidence to suggest that this trait is substantially related to either stressors or strains.

Individual differences in trait PA and NA are likely to persist over time. Personality differences in extroversion and neuroticism were found to antedate and predict differences in happiness over a period of years (Costa/McCrae 1980; Warr/Barter/Brownbridge 1983). This finding is presented by some as evidence to rule out the rival hypothesis that temporary affective states account for any observed relations.

Additional evidence suggests that affective wellbeing exhibits correlational stability with age. Costa, Zonderman, McCrae, Cornoni-Huntley, Locke and Barbano (1987) examined maturational changes and cohort differences on subjective wellbeing. The results indicated that older participants tended to be lower in both PA and NA, but longitudinal changes in overall wellbeing were not found. Stacey and Gatz (1991) reported similar cross sectional findings, with older cohorts reporting lower levels of both PA and NA. However, longitudinal analyses indicated small but significant changes toward decreased PA and NA, with NA registering the strongest effect size.

Are PA and NA related to anxiety and depressive disorders? Research by Watson, Clark and Carey (1988) has shown that NA is broadly associated with symptoms and diagnoses of both anxiety and depression (and as such is a predictor of psychiatric 
disorder), while PA is inversely related only to symptoms and diagnoses of depression. This prompted Tellegen (1985) to conclude that anxiety and depression might be better differentiated if the depression measures included more items tapping low PA, and anxiety measures had more items reflecting high NA. Tellegen's findings, therefore, are in agreement with the description and location of the anxiety and depression dimensions in Warr's (1990a) wellbeing model.

\section{Activity theories}

Feelings offer us a glimpse of what goes on in our flesh (Damasio 1994: 159).

Activity theorists consider that happiness is a by product of certain types of human activity. Happy people are those who are immersed in interesting activities. Aristotle was a major proponent of one of the earliest and most important activity theories. $\mathrm{He}$ maintained that happiness comes about through virtuous activity, that is, from activity that is performed well. The emphasis here is on the behaviour itself (the activity) rather than the achievement of some end point (i.e., a goal).

In a somewhat similar vein Gardner and Cummings (1988) have proposed an activation theory to predict wellbeing in the occupational setting. This theory maintains that humans have an idiosyncratic or 'characteristic level' of activation. Activation has been defined by Gardner and Cummings (1988: 83) as the “... state of neural excitation in the reticular activation system (RAS) of the central nervous system (the brain and spinal cord)". Emotional Intelligence was conceived by Mayer and Salovey (2000) as essentially about emotion, founded in modern understanding of the role of emotional circuits ('hot intelligences') in the brain.

Within this context, arousal is treated by the proponents of this theory as a manifestation of activation levels. A characteristic level of activation is one that allows the central nervous system to operate more effectively. The psychological benefits from operating at or close to one's characteristic level of activation are reflected in enhanced wellbeing or PA. Deviations from this characteristic level (either positive or negative) result in diminished central nervous system efficiency, with accompanying deterioration of motor responses and thought processes. For a detailed discussion on physiological-psychological links in affect refer to Hosie Sevastos and Cooper (2006: 41-45).

Activation theory further posits that individuals are motivated to maintain their characteristic level of activation through appropriate behaviours. However, in many situations the application of impact modifying behaviours is thwarted, for example, through machine pacing, rules and regulations, or supervisory directives. The theory, therefore, predicts that positive psychological outcomes would only result when the individual's ability to modify the situation is not constrained. Although activation theory makes similar predictions to those made by Hackman and Oldham's (1975) job characteristics model, or Karasek's (1979) job-strain model, it represents a very different interpretation of how certain job characteristics (e.g., task novelty, complexity, etc.) lead to certain outcomes. Unlike Hackman and Oldham's and Karasek's models, which are based on cognitive approaches, activation theory has relied more on the 
work of physiologists, physiological psychologists, and psychophysiologists (Gardner/ Cummings 1988).

Although activation theory presents a viable alternative to the other job design and job stress models, it has been largely ignored as a research topic in occupational and organisational psychology, due mainly to measurement difficulties. By contrast, the work of Karasek (1979), which makes similar predictions to those made by the activation theorists, has generated considerable research output in the last thirty years. Research based on the work of Karasek (1979) and associates has focused on the relationship between perceptions of stressful jobs and job related wellbeing and mental health (Caplan, Cobb, French, Harrison/Pinneau 1975; Cooper/Marshall 1978; Landsbergis 1988; Warr 1990b). This model posits that there is a synergistic relationship between job demands and control or job decision latitude; that is, the interactive effects of high job demands and lack of control produce a strain effect greater than the simple additive effect of these two variables. In his original formulation of the model Karasek (1979: 341) defined job decision latitude as a composite of 'decision authority' and 'intellectual discretion', and job demands as a measure of “... the psychological stressors involved in accomplishing the work load, stressors related to unexpected tasks and stressors of job-related personal conflict".

In a revision of the Job Strain Model Karasek and Theorell (1990: 58) redefined the combination of intellectual discretion and job decision authority as 'control', because "... in our opinion a high level of skill gives the worker control over which specific skills to use to accomplish the task". The key prediction from this model is that when job demands are very high and control is low, wellbeing suffers disproportionately. The revised model has also been expanded by the inclusion of a third variable that has been identified by other researchers in the literature as a 'buffer'. This variable is social support, and incorporates the constructs of supervisory and peer support. These three broad constructs (i.e. control, demands, and support) act interactively to determine the quality of the psychosocial work experiences of workers.

Figure 3 depicts a typology of jobs resulting from different combinations of job demands and job control. 'High strain' jobs are those with a combination of high job demands and low levels of control. 'Low strain' jobs have low levels of job demands and high levels of job control. 'Passive jobs' are those characterised by low job demands and low job control, resulting in learned helplessness as a way of coping.

When job demands and job control are simultaneously high these jobs would not be associated with strain because they are 'active jobs'. These jobs allow the individual to develop new behaviour patterns to mitigate the effects of high demands. Psychological strains are not great under these circumstances, because the energy generated by the job's many challenges is translated into action through effective problem solving (Karasek/Theorell 1990). Furthermore, research has shown that people with active jobs enjoy the highest material and psychological rewards (Karasek 1979).

Although low strain jobs, shown in the high control low demand quadrant in figure 3 , characteristic of self paced occupations, may be considered " ... a relative psychosocial paradise with low levels of psychological strain” (Karasek/Theorell 1990: 42), they are not considered desirable from a wellbeing and mental health perspective. 
Warr (1994c: 86) in particular has adopted a value laden position on this issue by suggesting that this 'passive contentment' view of mental health ought to be rejected in preference to the active involvement in the pursuit of challenging goals. A problem arises, however, if the strain is particularly severe or becomes chronic.

Figure 3: Demand control model (Source: Adapted from Karasek 1979: 288)

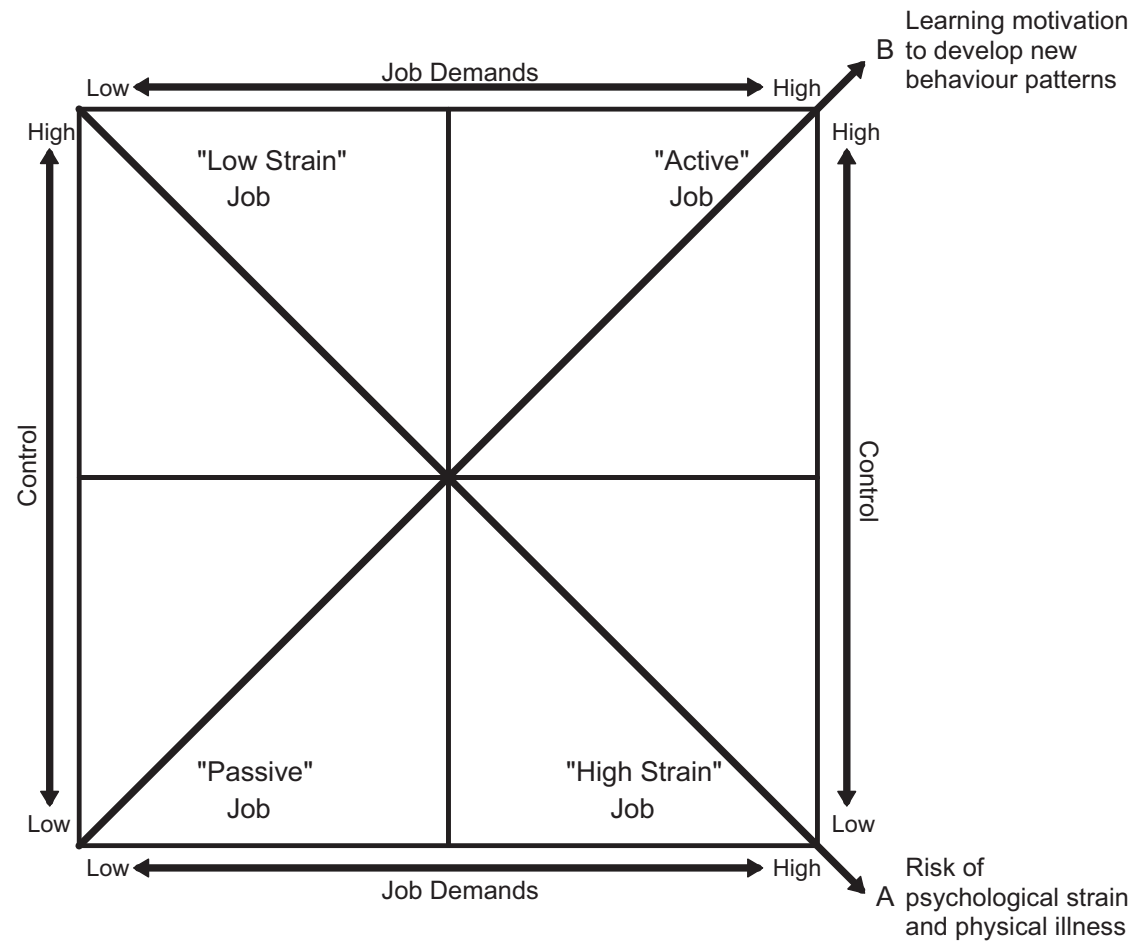

Employees undertaking highly complex jobs with exceptionally high levels of control, for example, may experience control as a significant demand in itself (Karasek /Theorell 1990). This may give rise to unacceptable levels of job-related anxiety (Birdi /Warr/Oswald 1995/Warr 1990a), and general psychological distress. A curvilinear relationship between certain job characteristics and wellbeing has also been proposed by Champoux (1980). This suggests that Warr's Vitamin Model may be considered a viable alternative to Karasek's model, because it addresses some of the anomalies found when the Karasek model is tested empirically. Warr (1990b); Landsbergis (1988); Spector (1987); and Payne and Fletcher (1983) were all unable to replicate the interactive effect of job demands and decision latitude of Karasek's (1979) Job Strain Model.

Researchers who have attempted to replicate Karasek's findings have invariably neglected to account for the interaction between job demands and decision latitude since both appear to have only 'main effects' on job satisfaction (Hurrell/McLaney 1989; Kasl 1989). Kauppinen-Toropainen et al. (1983: 201) found “... relatively low total explanatory power of the [Job Strain] model" questioned why only two job fac- 
tors were posited to underpin job strain. Fletcher (1991) argued that a more appropriate model should include a wider range of job features, such as social support. This perspective is consistent with the findings of Parkes, Mendham and von Rabenau (1994), Johnson (1991), and Parkes (1990 1991). Ganster (1989) has suggested that Karasek's findings exaggerated the role of control because it may be that job complexity (or challenge) is the more important predictor of psychological health outcomes.

Sevastos (1996) demonstrated that enthusiasm, depression, anxiety, and comfort, relaxation, and intrinsic job satisfaction could be explained by two orthogonal dimensions. The first dimension was labelled task complexity and consisted of supervisory support, skill utilisation, role clarity and feedback, which were related primarily to intrinsic job satisfaction (i.e. cognitive evaluations), and to a lesser extent enthusiasm, anxiety, and depression (inverse association); while the second dimension was defined by low work pressure and role ambiguity, which were related to anxiety (inversely), relaxation, enthusiasm (inversely), and depression (i.e. all the affective states). When combined, these dimensions provided a job typology that is consistent with Karasek's passive-active jobs, represented in figure 4 diagonally from quadrant 1 to quadrant 4, and low strain-high strain, shown diagonally from quadrant 3 to quadrant 2 jobs respectively.

Figure 4: Attitudinal and affective outcomes of complexity on work pressure (Source: Sevastos 1996: 78)

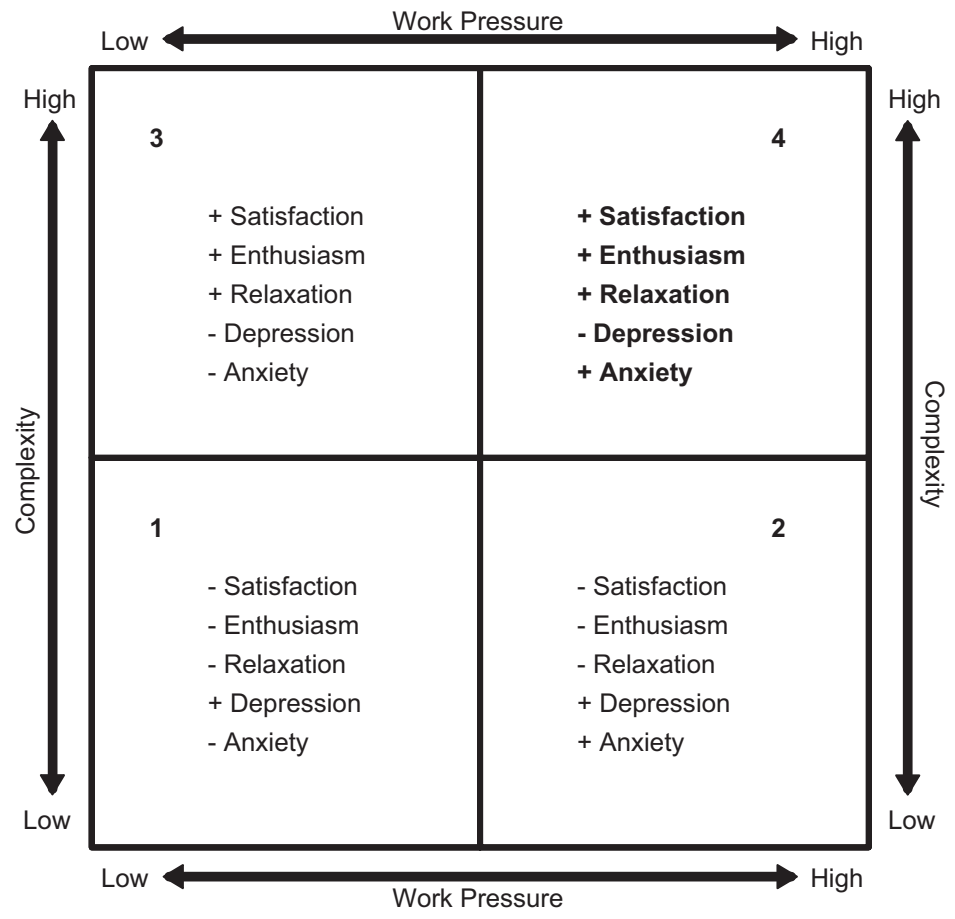

Outcomes depicted in figure 4 are associated with 'passive' jobs (Low Skill Variety, Lack of Autonomy, Feedback, Skill Utilisation, Supervisory Support, High Role Ambiguity and Low Work Pressure), 'high strain' jobs (Low Skill Variety, Autonomy, 
Feedback, Skill Utilisation, Supervisory Support and High Work Pressure), 'low strain' jobs (High Skill Variety, Autonomy, Feedback, Skill Utilisation, Supervisory Support and Low Work Pressure), and 'active' jobs (High Skill Variety, Autonomy, Feedback, Skill Utilisation, Supervisory Support, Clear Role Definition and High Work Pressure) respectively.

'Passive jobs' (see quadrant 1) are characterised by outcomes, such as dissatisfaction, lack of enthusiasm, lack of relaxation, depression and low anxiety. The outcomes for 'high strain' jobs outcomes are described in quadrant 4 comprise dissatisfaction, lack of enthusiasm and relaxation, depression and anxiety. For 'low strain' jobs, the outcomes are indicated by satisfaction, enthusiasm, relaxation, and low depression and anxiety, as shown in quadrant 3. Outcomes for 'active jobs' are satisfaction, enthusiasm, relaxation, anxiety, low depression, and intrinsic job satisfaction (quadrant 4).

These jobs have the potential to provide a worker with 'flow' experiences (Csikszentmihalyi 1990) due to the challenging nature of the work, but only if the complexity of the task is matched with self efficacy to meet these challenges. In this instance, anxious apprehension (Heller/Nitschke 1998) characterised by approach tendencies would be associated with positive valence and experienced as pleasant affect (i.e., eustress) consistent with the overall hedonic tone of satisfaction, enthusiasm, and relaxation. A differential source for depression and anxiety, therefore, is evident in Sevastos's (1996) model (see figure 4).

This analysis provides evidence that job features are differentially related to psychological outcomes, an observation also made by Warr (1990a). Sevastos (1996) concluded that the additive combination of the independent variable set (i.e. the job features), when related to the intrinsic job satisfaction and wellbeing set, impacted differentially on the workers, creating either psychological distress or affective wellbeing depending on the level of task complexity and job pressure. This generalised psychological distress or wellbeing may be attributed to a cognitive mechanism that can either amplify or dampen affect of similar hedonic tone (Diener et al. 1991a).

For example, there is evidence from the clinical literature (e.g., Clark/Beck/Stewart 1990), that the comorbidity of anxiety and depression is qualitatively different from either of these conditions considered separately, and is indicative of "... a more severe form of psychological distress" (Clark et al. 1990: 153). The psychological impact on the worker, therefore, would be consistent with a 'synergistic approach', even though the two sets of independent variables may act additively. These conditions are present in quadrant 2 of figure 4, where anxiety and depression co-occur. The longstanding argument related to Karasek's demand-control model, therefore, whether the influence of the independent variables on wellbeing is additive or synergistic, appears to be a moot point (Sevastos 1996: 95).

The Demand Control Model predicted that enriched job characteristics are associated with job satisfaction and low depression, and impoverished jobs are normally associated with job dissatisfaction and depression. As such, high work pressure is normally associated with high anxiety, while low pressure is associated with low anxiety. Thus, effective employees are predicted to report positive satisfaction, enthusiasm, relaxation, eustress, and low depression, as evidenced and tested by Sevastos's (1996) 
proposed Four Factor Model of Affective Wellbeing. Consistent with the Demand Control Model, Iverson and Erwin (1997) have predicted that the greater sense of self efficacy may be reflected in jobs with a higher degree of task engagement.

However, employees experiencing a persistent high level of anxiety (i.e. eustress) may not experience depression and job dissatisfaction, because important job content variables, such as skill utilisation; feedback; role clarity; and superior support, are available at high levels. Stress is either stimulus (cause), or response (symptoms), of worker reactions to their environment that has been separated into positive (eustress) and negative (distress) effects on individuals (Nankervis/Compton/McCarthy 1996). Eustress represents the positive stress associated with achievement and exhilaration, like meeting challenges (Selye 1974). Distress refers to the negative aspects of stress, like feelings of inadequacy, insecurity, helplessness or desperation that result from too much or not enough pressure or tension (Selye 1974).

\section{Telic theories (End State theories)}

The central proposition of Telic or End State theories is that affective wellbeing is attained when certain inherent human needs are satisfied, such as competence or aspiration (Diener 1984). Warr's (1994c), and Ryff and Keyes's (1995) models fall into Telic or endpoint theories of wellbeing. The main characteristic of a Telic or End State theory, is that wellbeing is achieved when some needs (e.g., competence, aspiration, etc.), either inborn or learned, are fulfilled. The argument is being made that if these needs are truly universal, their fulfilment should be associated with happiness in all cultures. However, it is unlikely that consensus among researchers will be achieved in identifying universal components of mental health (Warr 1994c).

A consolidated theory of employee mental health is overdue, given the confused and desegregated nature of research in the area. Warr's (1986; 1987 1994a; Warr 2007) Vitamin Model synthesised the bulk of research and theorising about job-related mental health. By integrating the existing knowledge, Warr constructed a comprehensive model of mental health and jobs (see Hosie/1994; Kelloway/Barling 1991; Ross 1989). Warr's Vitamin Model provided a cohesive schematic framework that incorporated complex and interrelated variables that influence employee mental health. Warr departed from the dominant mental health paradigm that considered job satisfaction to be axiomatic to affective wellbeing in the workplace. Long before 'affect' and 'emotions' research made its appearance in the occupational literature, Warr (1986: 163167) stated that:

We must move away from the conventional narrow focus upon 'job satisfaction'. This orthodoxy and its associated from of measurement has greatly hampered the development of occupational psychology. We must of course work to understand job-related well-being and the factors influencing it, but we need a shift in perspective away from job satisfaction. It now seems desirable to focus upon three dimensions of measurement, including arousal as well as pleasure in our theories and measuring instruments.

Twelve features of jobs and environmental categories applicable to job settings are argued by Warr (2007: 132) to underlie affective wellbeing: opportunity for control; opportunity for skill use; externally generated goals; variety; environmental clarity; contact with others, availability of money; physical security; valued social position, sup- 
portive supervision, career outlook and equity. The third part of Warr's framework examined the differences between people.

While the overall Vitamin Model is intended to be 'situational', it is also 'enabling' and assumes that people are able to shape their environment and influence its possible impact on them. Aspects of the environment have the potential to impair or promote affective wellbeing, when present at critical levels. The enabling contribution of affective wellbeing to employees' job performance is likely to be most noticeable at high or low critical levels. This assertion leads to speculation that high performing employees are likely to experience periods of heightened anxiety followed by periods of relaxation, while maintaining an overall sense of positive affective wellbeing. Highly motivated employees who desire challenges may react to risks in ways that raise their anxiety level without negatively impacting on their affective wellbeing. Therefore, it seems worthwhile to extend Warr's model to test whether job-related anxiety, when linked to aspirations, leads to altered performance.

Features of jobs and other environments that Warr (1987, 1990b, 1992, 1994c, 1996) assumed to underlie 'positive' mental health. These categories are further deconstructed to create a "... differentiated treatment of the environment" (Warr 1987: 9). There are five components Warr's (1994a) model: affective wellbeing; competence; aspiration; autonomy; and integrated functioning. These dimensions are interrelated in the work context Warr's Vitamin Model posits that environmental features of jobs impact on affective wellbeing. As with the physical effects of vitamins, the model is conceived as being analogous to aspects of the work environment. Collectively, vitamins have a beneficial effect (when taken in moderation), or a detrimental effect (if taken in excessive doses), on affective wellbeing. Moreover, environmental features can promote or decrease mental health, as illustrated in figure 3 . These job features impact adversely on affective wellbeing in a way similar to the toxic effect of ingesting vitamins $\mathrm{A}$ and $\mathrm{D}$ in large quantities.

Conversely, taking large doses of vitamins $\mathrm{C}$ and $\mathrm{E}$ has no known adverse effects. Thus, the availability of associated environmental features, like money, physical security, and valued social position is analogous to the effect of vitamins $C$ and $E$ on human physiology. These features increase affective wellbeing up to a critical point, then level off, maintaining what Warr (1986) terms a 'constant effect', as represented by the CE curve in figure 5 .

Warr $(1986,2007)$ argued that the Vitamin Model predicts those opportunities for control and skill use (or job decision latitude) that result in a curvilinear relationship with affective wellbeing. However, while a subsequent test of the model by Warr (1990b) supported this prediction, there was no evidence for the moderating effect of job decision latitude on job demands as predicted by Karasek's (1979) Job Strain Model. As such, Warr's Vitamin Model may be considered a viable alternative to Karasek's Job Strain Model by virtue of providing a plausible explanation of the anomalies encountered when Karasek's model is empirically tested. 
Figure 5: Vitamin model (Source: Warr 1987: 10)

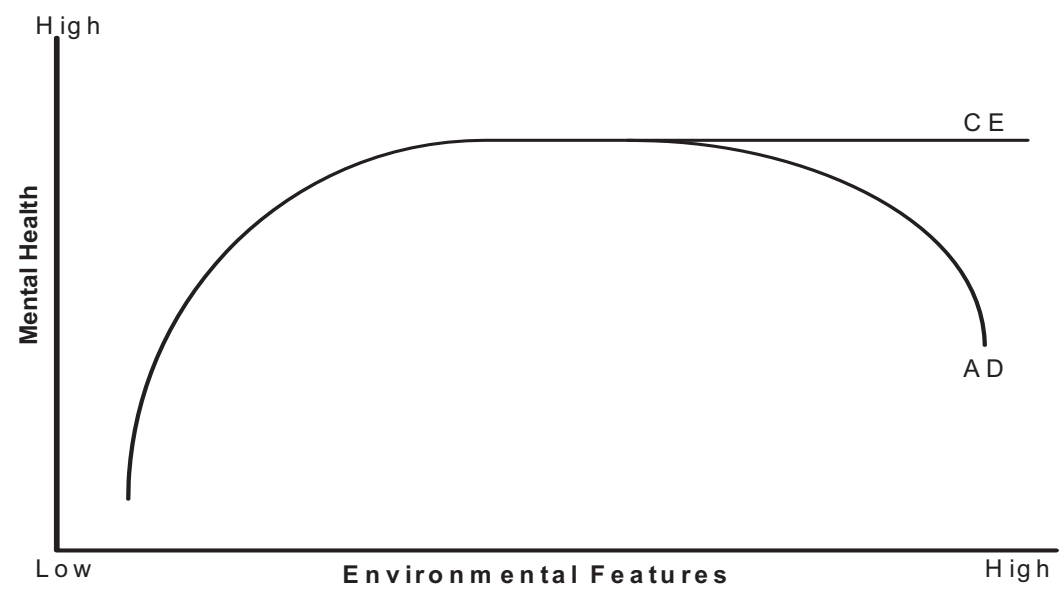

\section{Super factor (second-order level) model}

Published models of affective wellbeing converge on three components, but differ in their conception of the constituent parts (Diener 1984). Ryff and Keyes's (1995) Super Factor (Second-Order Level) Model of affective wellbeing is theoretically underpinned by the convergence of a number of approaches from developmental psychology (Erikson 1959), from clinical psychology (Allport 1961; Jung 1933; Maslow 1968; Rogers 1961), and from affective wellbeing (Birren/Renner 1980). Six dimensions of context-free psychological wellness were derived from "... multiple theoretical accounts of positive functioning" (Ryff/Keyes 1995: 4) to form the Super Factor Model.

Ryff and Keyes's (1995) research used confirmatory analytic procedures to create a second-order factor model of affective wellbeing. The data fitted the proposed hierarchical structure of affective wellbeing better, although not adequately for acceptable criteria of fit, compared to alternative models of affective wellbeing, included first order factors. A two factor model of positive and negative affectivity and a six factor model emerged from the analysis, after subtracting the higher order factor latent structure.

The Super Factor Model includes six distinct components of psychological wellness: self acceptance; environmental mastery; purpose in life; positive relations with others; personal growth; and autonomy. The Super Factor Model subsumed a number of the dimensions identified in Warr's (1994b) wellbeing and mental health model, including: self acceptance (positive evaluations of oneself); environmental mastery (the ability to deal successfully with the environment); purpose in life (a sense of purpose and meaning in one's life); positive relations with others (the existence of quality interpersonal relations); personal growth (a sense of continued growth and development as a person); and autonomy (self determination).

As such, there is overlap between the Super Factor Model and Warr's Model. Warr's notion of autonomy corresponds to Ryff and Keyes's (1995) conceptualisation of autonomy. Likewise, Warr's aspiration dimension, the extent to which a person strives to achieve goals through purposeful activity, corresponds closely to Ryff and 
Keyes's (1995) personal growth dimension: the tendency to strive for independence and self regulation in one's life. Moreover, the dimension of Warr's competence, an ability to deal effectively with life's problems, closely resembled Ryff and Keyes's (1995) dimension of environmental mastery.

In the absence of a universally applicable definition of wellbeing or mental health, both Warr's (1994b) and Ryff and Keyes's (1995) models adopted a relativist position, imbued by Western values. In addition, these models are derived from both categorical and process theories that converged on three affective wellbeing or mental health dimensions. When the Super Factor Model dimensions are considered in combination they represent a comprehensive perspective of wellbeing or mental health. Despite these similarities, the models are not identical and different conceptualisations of the components of wellbeing and mental health are evident.

Table 4: Conceptual relationships between affective wellbeing theories, models, schools and streams of research

\begin{tabular}{lccc}
\hline Models/Schools/Streams of Research & \multicolumn{2}{c}{$\begin{array}{c}\text { Typologies of } \\
\text { Affective Wellbeing }\end{array}$} \\
\hline & Dispositional & Activity & Telic \\
\cline { 2 - 4 } Positive and Negative Affect (Bradburn 1969) & $\sqrt{ }$ & \\
Dispositional Approach to Job Satisfaction (Staw/Ross 1985) & $\sqrt{ }$ & \\
Happy-productive worker thesis (Cropanzano/Wright 2001; Cropanza- & $\sqrt{ }$ & $\sqrt{ }$ \\
no/Wright 1999; Staw 1986; Wright/Cropanzano 1997/2000; Wright/ & & & \\
Cropanzano/Denney/Moline 2002; Wright/Staw 1999b; Wright/Staw 1999a) & & $\sqrt{ }$ & \\
Activation theory (Gardner/Cummings 1988) & & $\sqrt{ }$ & $\sqrt{ }$ \\
Positive and Negative Affect (Brief et al. 1988) & & $\sqrt{ }$ & $\sqrt{ }$ \\
Model of Hemispheric Specialisation (Tucker/Williamson 1984) & & $\sqrt{ }$ & $\sqrt{ }$ \\
Job Strain Model (Karasek 1979) & & & $\sqrt{ }$ \\
Demand Control Model (Karasek/Theorell 1990) & & $\sqrt{ }$ \\
Super Factor Model (Ryff/Keyes 1995) & & $\sqrt{ }$ \\
Four Factor Model of Affective Wellbeing (Sevastos 1996) & & & $\sqrt{ }$ \\
Vitamin Model (Warr 1987, 1990b, 1992, 1994c, 2007, 1996) & & & \\
\hline
\end{tabular}

\section{Future reviews}

There are several areas of the literature that would compliment and extend this review. Affective wellbeing and intrinsic job satisfaction in the workplace is not normally conceived and measured in relation to employees' and managers performance. Evidence to support the physiological basis of emotion is emerging. Emotional intelligence is a broad concept that can be related to many of the illustrated elements of the composite framework of the theories, disciplines and schools. A summarised review follows of the work seminal to extending upon this theoretical review affective wellbeing in the workplace.

\section{Job satisfaction}

Job satisfaction has been found to be an important influence on mental/psychological wellbeing, particularly in relation to burnout, self esteem, depression and anxiety. A 
differentiation was established between affective wellbeing and extrinsic job satisfaction, which is mainly concerned with cognitions. Intrinsic job satisfaction is related to affective wellbeing but is a distinct construct. Job-related affect has exhibited acceptable levels of discriminant validity with intrinsic job satisfaction and should be incorporated into research that accounts for cognition's potential to contribute to job-related affective wellbeing.

Enriched or complex jobs, such as those undertaken by managers, are generally associated with increased job satisfaction, motivation, and work performance. Enthusiasm and depression are more strongly related to intrinsic job satisfaction than are anxiety and relaxation. While intrinsic job satisfaction measures are presumed to reflect cognitive evaluations of the working environment, they also capture substantial levels of job-related affect. Job satisfaction has been established as an important contributor to mental and psychological health problems in the workplace (Faragher/ Cass/Cooper 2005).

Several decades of research have informed the conceptualisation of job satisfaction as a person's cognitive appraisal of the working environment (Organ/Near 1985). Organisational Behaviour theorists have extensively researched motivational aspects of intrinsic work attitudes such as job satisfaction, a multi dimensional construct that is strongly influenced by disposition and mood. Hoppock (1935) initially conceived of job satisfaction as the aggregate of dispositional and situational influences. Others have suggested that job satisfaction is the positive emotional reaction and cognition a person has towards the job (Oshagbemi 1991).

Some support exists for the view that certain aspects of job satisfaction may be genetically determined through NA (Arvey et al. 1989; Staw/Bell/Clausen 1986). While it seems unlikely that job satisfaction (i.e. the attitude) is inherited, it may be possible that some personality characteristics associated with job satisfaction are partially determined by genetic factors (Arvey et al. 1989). If this is the case, there is a prospect that some genetic sources of job satisfaction operate through NA, PA, or both. For people with a predisposition to negatively construe life events (i.e. trait NA), this tendency may be partially inherited and would register as part of a job satisfaction score (Chen/Spector 1991).

Other findings suggest that both NA and PA exert influence on a variety of variables, like job satisfaction that are, for the most part, situationally determined (Watson/Clark 1984). Cropanzano, James, and Konovsky (1993), for example, found that both PA and NA were related to a global measure of job satisfaction, while a recent meta-analytic study reported a mean correlation of $r=.49$ between PA and job satisfaction (Connolly/Viswesvaran 2000).

However, Ilies and Judge (2003) concluded that PA and NA has a strong genetic mediating effect on job satisfaction (about 45\%). Although the debate has not been settled in the literature as to whether job satisfaction is inherited, as the studies reported above would suggest, or influenced by situational determinants as others have argued (Davis-Blake/Pfeffer 1989), "it is time for dispositional researchers to move from their defensive posture ... to a more ambitious agenda for understanding the role of personality in organizational settings" (Staw/Cohen-Charash 2005: 73). This 
requires a new way of approaching job satisfaction and affect. The relative importance of the cognitive and affective aspects to intrinsic job satisfaction debate continues into employees' performance.

\section{Relationship between intrinsic job satisfaction and affective wellbeing}

Research into antecedents to job satisfaction has focused on broadening the theoretical base of causal factors, including dispositional effects (Agho/Mueller/Price 1993; Judge 1993; Judge et al. 1998), perceptual mediators (Carlopio/Gardner 1995), and organisational obstacles (Brown/Mitchell 1993). Despite such extensive investigation, causal relationships concerning antecedents to, and consequences of, job satisfaction are still not settled (Cranny/Smith/Stone 1992).

Some researchers, such as Agho, Mueller and Price (1992) considered that job satisfaction indicated the extent to which an individual likes a job. Other researchers (e.g., Clegg/Wall/Kemp 1987; Evans 1986) found that job satisfaction represents a positive affective orientation towards a job, or to intrinsic and extrinsic facets of a job. These findings led many researchers to operationalise affective wellbeing as job satisfaction (Brayfield/Rothe 1951; Iaffaldano/Muchinsky 1985). Satisfaction with the type of work undertaken has been found to be closely associated with other specific satisfactions and with overall job satisfaction (Cook 1981). As stated, Warr $(1987,1992)$ has argued that affective wellbeing is more than job satisfaction, while Judge et al. (2001) concluded from a meta-analysis that job satisfaction does not equate to affect.

Within Warr's conceptual framework of affective wellbeing, job satisfaction is located in the horizontal axis in a space defined by the orthogonal axes of arousal and pleasure as shown in Figure 1. Warr argued that when measuring job satisfaction “... no consideration is taken of level of arousal" (Warr 1986: 163). This implies that job satisfaction, shown on the horizontal axis as 'pleasure-misery' in Figure 2 captures mainly cognitions, while anxiety-contentment and depression-enthusiasm capture affect. This view is inconsistent with findings by Brief, Burke, George, Robinson and Webster (1988), who developed a Job Affect Scale that permitted job satisfaction to be partitioned into affect and cognitions. Actually, job satisfaction in general is probably closer to a state of 'bovine contentment' than an actual state of happiness (Wright/Staw 1999b, 1999a). However, if job satisfaction is conceptualised as an attitude then it is necessary to include both cognitions and affect. Sevastos (1996) has demonstrated that there is a substantial overlap between intrinsic job satisfaction scales and affect scales, indicating they are not exclusively cognitive evaluations of a person's working environment.

\section{Relationship between affective wellbeing and job performance}

Wright and Staw (1999b, 1999a) and others such as Harter et al. (2002) have rekindled the debate over whether happy workers are also more productive. Wright and Staw (1999a: 11) found mixed support for the happy-productive worker thesis but concluded that " $\ldots$ the dispositional measure of affect is a more successful predictor of rated performance". In the process of reviving this debate, Wright and Staw (1999a: 3) have highlighted an important methodological consideration, stating that "... dispositional rather than state affect may be a stronger operationalisation of the happy- 
productive worker thesis". Assessments of dispositional affect provided a closer fit for individual based measures of performance than did measures of affective state or mood (Cropanzano et al. 1993; Cropanzano/Wright 2001; Cropanzano/Wright 1999; Wright/ Staw 1999b, 1999a). There is mixed empirical support for the relationship between job satisfaction and performance. A meta-analysis by Judge et al. (2001) concluded that a re-conceptualisation of the satisfaction-performance relationship was warranted.

This view found support in a study by Staw and Barsade (1993). After controlling for the effects of general mental ability, age, gender, and years of work experience, dispositional PA predicted managerial performance (decision making and interpersonal behaviour), and overall managerial potential, supporting the hypothesis of the happier-and-smarter worker. In the same vein Ilies and Judge (2003) consider trait affectivity a more important predictor of organisational performance than job satisfaction, because of its stability over time, as opposed to the situational determinants of job satisfaction. However, as Weiss and Cropanzano (1996) have argued in their Affective Events Theory (AET), affective states fluctuate over time and current satisfaction levels may reflect recent events and personal affect histories. Suh, Diener, and Fujita (1996) found, for example, that although an individual's level of extraversion and neuroticism predicted wellbeing over a period of years, recent events did also matter.

\section{Managers' training and development issues}

Traditionally, task relevant improvements (e.g., job design) or motivational techniques (e.g., goal setting and reinforcement) or improvements in ability (e.g., training and development) have been used to improve performance. Essentially, these interventions concentrate on the cognitive aspects of managers' jobs. Organisations that are most successful at developing managers provide extensive development and coaching, and measurement of progress that is coupled to an appropriate reward system (HayGroup 1999).

Executive management development is increasingly being seen as involving personal development related to the way in which the individual deals with work/life issues, stress, and health (Hall 1995). By their very nature, developing self awareness, self insight and self understanding are within an individual managers' capacity for development. Nevertheless, such a distinction is important. A shift in attitude and emphasis is needed for this to occur, beginning with recognition of the importance of affective wellbeing in the workplace and the contribution of intrinsic job satisfaction to managers' performance. Certain affective wellbeing states (e.g., Enthusiasm, Anxiety and Relaxation) were found, by Hosie and Sevastos (Hosie/Sevastos 2007) to influence managers' likelihood of achieving optimal performance. Developing these competencies is one way of ameliorating the debilitating effects of stressors on individual managers.

Since behaviour is something that can be changed and developed, the emphasis should be on developing aspect of human potential capable of enhancing managerial performance. Creating ingrained patterns of thoughts, feeling and behaviour may require an extensive development effort over several months, and may require a further 3-5 years to fully develop (Chernis/Goleman 2001). Emotional intelligence may be 
best defined in terms of abilities concerning the recognition and regulation of emotion in the self and others (Ashkanasy/Daus 2005). Landy (2005) considered it would be intriguing to examine emotional intelligence as a predictor of the constructs worker personality, performance, satisfaction, affect, and disposition.

Training and development efforts have not always distinguished between cognitive learning and emotional learning. An "... emotional competence is a learned capability based on emotional intelligence that results in improved job performance" (Goleman 1999: 25). Emotional competence requires that emotional learning be recognised and given the same prominence as cognitive learning. Developing emotional intelligence takes time and most of all, commitment from organisations and individuals. Benefits that flow from a well developed emotional intelligence for both the individual and the organisation, are likely to make the effort and cost worthwhile (Goleman 1999). Finding ways of improving self efficacy is important to furthering our understanding of how motivation influences performance that may translate into increased organisational productivity. This can be achieved by changing work environments to be more flexible and intrinsically rewarding.

A growing body of research on emotional learning and behaviour change suggests that it is possible to help people of any age to become more emotionally intelligent at work. However, many programmes designed to do so fail to recognise the difference between cognitive and emotional learning. According to Goleman (1998: 317), "Companies are naive in how they spend their development dollars in training for people skills - they can get a far better return on their investment if they do it right ... The rules of work are changing. We're being judged by a new yardstick: not just how smart we are, or our expertise, but also how well we handle ourselves and each other". This line of reasoning reinforces the need to rethink how we approach developing soft skills in the workplace.

Cognitive learning involves fitting new data and insights into existing frameworks of association and understanding, extending and enriching the corresponding neural circuitry. Emotional learning involves more than this, it requires managers to also engage their neural circuitry which stores the repertoire of social and emotional habit. Changing habits, such as learning to approach people positively instead of avoiding them, to listen better or to give feedback skilfully are more challenging tasks than simply adding new information to old. Individual motivational factors also make social and emotional learning more difficult and complex than purely cognitive learning.

Emotional learning often involves ways of thinking and acting that are more central to a person's identity. Goleman (1998) has specifically linked the ability to influence others to a person's emotional intelligence. However the importance of emotional intelligence needs to be kept in perspective, "Emotional intelligence skills are synergistic with cognitive ones: top performers have both" (Goleman 1998: 21). Developing managers' emotional competencies requires a broad and sophisticated array of development tools. Traditional training needs to be blended with a variety of ongoing planned developments such as career assignments and individual coaching. A period of months involving ongoing coaching, encouragement, peer support, modelling and on-the-job practice is necessary (HayGroup 1999). Such initiatives have important resource implications for organisations and therefore demand careful consideration. 


\section{Summary and conclusions}

This article examined the philosophical roots and contemporary understandings of happiness, the most fundamental aspect of affective wellbeing. The nature of happiness was explored, beginning with the philosophical roots and ending with contemporary understandings of the phenomenon. Happiness is conceived as an emotional state, and affective wellbeing as an antecedent of happiness. Work-related affective wellbeing was categorised as Dispositional, Activity or Telic. These typologies provide a useful framework for conceiving theories about affective wellbeing. Warr's (1986; 1994b) Vitamin Model, Karasek and Theorell's (1990) Job Strain Model, and Staw and Ross's (1985) dispositional approach to job satisfaction are theoretical frameworks that make useful predictions about affective wellbeing.

Dispositional theories consider affective wellbeing to be an integral part of a person's psychological makeup. Exogenous work circumstances are largely discounted as contributing to a person's happiness, so situational factors are not considered to contribute a great deal to an individual's affective wellbeing. In contrast, Activity theorists expound an alternative 'process' view of the world that focuses on a person's behaviour. Evidence supporting a monopolar model of affective wellbeing structure, consisting of Enthusiasm, Depression, Anxiety and Relaxation is theoretically and empirically robust. Happiness is considered a by product of human activity; happy people immerse themselves in interesting activities. Positive affective outcomes are predicted to result when a person's capacity to modify a situation is unconstrained.

Proponents of Telic theory believe affective wellbeing is attained when some inherent or learned needs are satisfied, such as the need for competence or aspiration. They also believe consensus among researchers will eventually result in the identification of universal components of mental health. Warr's Vitamin Model represents the most comprehensive synthesis of research and theories into occupationally related affective wellbeing. The Vitamin Model of mental health is far more inclusive, comprehensive and supported by empirical evidence than competing models.

\section{References}

Ackrill, J. L. (1963): Aristotle's Categories and De Interpretatione (J. L. Ackrill, Trans.). Oxford, United Kingdom: Oxford University Press.

Adolphs, R./Tranel, D./Damasio, H./Damasio, A. R. (1995): Fear and the human amygdala. In: Journal of Neuroscience, 15: 5879-5891.

Agho, A./Price, J. L./Mueller, C. W. (1992): Discriminant validity of measures of job satisfaction, positive affectivity and negative affectivity. In: Journal of Occupational and Organizational Psychology, 65(12): 185-196.

Agho, A. O./Mueller, C. W./Price, J. L. (1993): Determinants of employee job satisfaction: An empirical test of a causal model. In: Human Relations, 46(8): 1007-1027.

Allport, G. W. (1961): Pattern and growth in personality. New York: Holt, Rinehart/Winston.

Argyle, M./Martin, M. (1991): The psychological causes of happiness. In: F. Stack, M. Argyle/N. Schwarz (Eds.): Subjective well-being: An interdisciplinary perspective (pp. 119-139). New York: Pergamon Press.

Aristotle. (1952): Nicomachean ethics (W. D. Ross, Trans.). Chicago: William Benton, Encyclopaedia Britannica, Inc.

Arvey, R. D./Bouchard, T. J./Segal, N. L./Abraham, L. M. (1989): Job satisfaction: Environmental and genetic components. In: Journal of Applied Psychology, 74(2): 187-192. 
Ashkanasy, N. N./Daus, C. S. (2005): Rumors of the death of emotional intelligence in organizational behavior are vastly exaggerated. In: Journal of Organizational Behavior, 26(4): 441-452.

Bagnall, D. (2004, December 15): Science of happiness: The secret of happiness is the holy grail of the new millennium. In: The Bulletin, Features, Summer Reading, A6.

Birdi, K./Warr, P. B./Oswald, A. (1995): Age differences in three components of employee well-being. In: Applied Psychology: An International Review, 44: 345-373.

Birren, J. E./Renner, V. J. (1980): Concepts and issues of mental health and aging. In: J. E. Birren/R. B. Sloane (Eds.): Handbook of mental health and aging. Englewood Cliffs, New Jersey: Prentice Hall: 3-33.

Bradburn, N. M. (1969): The structure of psychological well-being. Chicago, Illinois: Aldine.

Brayfield, A. H./Rothe, H. F. (1951): An index of job satisfaction. In: Journal of Applied Psychology, 35(5): 307-311.

Brief, A. P./Burke, M. J./George, J./Robinson, B. S./Webster, J. (1988): Should negative affectivity remain an unmeasured variable in the study of job stress? In: Journal of Applied Psychology, 73(2): 193-198.

Brown, K. A./Mitchell, T. R. (1993): Organisational obstacles: Links with financial performance, customer satisfaction and job satisfaction in a service environment. In: Human Relations, 46(6): 725-757.

Burke, M. J./Brief, A. P./George, J. M./Roberson, L./Webster, J. (1989): Measuring affect at work: Confirmatory analyses of competing mood structures with conceptual linkages to cortical regulatory systems. In: Journal of Personality and Social Psychology, 57(6): 1091-1102.

Caplan, R. D./Cobb, S./French, J. P./Jr, Harrison, R. V./Pinneau, S. R./Jr. (1975): Job demands and worker health. Ann Arbor, Michigan: The Institute for Social Research, The University of Michigan.

Carlopio, J./Gardner, D. (1995): Perception of work and workplace: Mediators of the relationship between job level and employee reactions. In: Journal of Occupational and Organizational Psychology, 68(4): 321-326.

Champoux, J. (1980): A three sample test of some extensions to the Job Characteristics Model of work motivation. In: Academy of Management Journal, 23: 466-478.

Chen, P. Y./Spector, P. E. (1991): Negative affectivity as the underlying cause of correlations between stressors and strains. In: Journal of Applied Psychology, 76(3): 398-407.

Chernis, C./Goleman, D. (Eds.). (2001): The emotionally intelligent workplace: How to select for, measure, and improve emotional intelligence in individuals, groups, and organizations. San Francisco, California: Jossey-Bass.

Clark, D. A./Beck, A. T./Stewart, B. (1990): Cognitive specificity and positive-negative affectivity: Complimentary or contradictory views of anxiety and depression? In: Journal of Abnormal Psychology, 99(2): 148-155.

Clegg, C./Wall, T./Kemp, N. (1987): Women on the assembly line: A comparison of the main interactive and explanations of job satisfaction, absence and mental health. In: Journal of Occupational Psychology, 60(4): 273-287.

Connolly, J. J./Viswesvaran, C. (2000): The role of affectivity in job satisfaction: A meta-analysis. In: Personality and Individual Differences, 29: 265-281.

Cook, J./Hepworth, S. J./Wall, T. D.// Warr, P. B. (1981): A compendium and review of 249 work review measures and their use. London, United Kingdom: Academic Press.

Cooper, C. L. (1996): Handbook of stress, medicine and health. London, United Kingdom: CRC Press.

Cooper, C. L./Marshall, J. (1978): Sources of managerial and white collar stress. In: C. L. Cooper/R. Payne (Eds.): Stress at work. New York: Wiley: 81-105.

Cooper, C. L./Payne, R. (Eds.): (1988): Causes, coping and consequences of stress at work. Chichester, New York: Wiley.

Costa, P. T./McCrae, R. R. (1980): Influence of extraversion and neuroticism on subjective well-being: Happy and unhappy people. In: Journal of Personality and Social Psychology, 38(4): 668-678.

Costa, P. T./McCrae, R. R. (1987): Validation of the five-factor model of personality across instruments and observers. In: Journal of Personality and Social Psychology, 52(1): 81-90. 
Costa, P. T./Zonderman, A. B./McCrae, R. R./Cornoni-Huntley, J./Locke. B.Z./Barbano, H. E. (1987): Longitudinal analyses of psychological well-being in a national sample: stability of mean levels. In: Journal of Gerontology, 42: 50-45.

Cranny, C./Smith, P./Stone, E. A. (1992): Job satisfaction: How people feel about their jobs. New York: Lexington Books.

Cropanzano, R./James, K./Konovsky, M. A. (1993): Dispositional affectivity as a predictor of work attitudes and job performance. In: Journal of Organizational Behavior, 14(6): 595-606.

Cropanzano, R./S./Wright, T./A. (2001): When a 'happy' worker is really a 'productive' worker: A review and further refinements of the happy-productive worker thesis. In: Consulting Psychology Journal, 53(3): 182-199.

Cropanzano, R./S./Wright, T. A. (1999): A five-year study of the relationship between well-being and performance. In: Journal of Consulting Psychology, 51: 252-265.

Csikszentmihalyi, M. (1990): Flow: The psychology of optimal experience. New York: Harper/Row.

Dalai Lama/Cutler, H. C. (1999): The art of happiness: A handbook for living. Adelaide, South Australia: Griffin Press.

Damasio, A. R. (1994): Descartes' error: Emotion, reason, and the human brain. New York: Grosset/Putnam.

Davis-Blake, A./Pfeffer, J. (1989): Just a mirage: The search for dispositional effects in organizational research. In: Academy of Management Review, 14(2): 385-400.

Delbridge, A./Bernard, J. R. L./Blair, D./Peters, P./Butler, S. (Eds.). (1996): The Macquarie dictionary (Revised, 3rd ed.). Sydney, New South Wales: The Macquarie Library.

Diener, E. (1984): Subjective well-being. In: Psychological Bulletin, 95(3): 542-575.

Diener, E./Colvin, R. C./Pavot, W. G./Allman, A. (1991a): The psychic costs of intense positive affect. In: Journal of Personality and Social Psychology, 61(3): 492-503.

Diener, E./Iran-Nejad, A. (1986): The relationship in experience between different types of affect. In: Journal of Personality and Social Psychology, 50: 1031-1038.

Diener, E./Larsen, R. J./Levine, S./Emmons, R. A. (1985): Intensity and frequency: Dimensions underlying positive and negative affect. In: Journal of Personality and Social Psychology, 48(5): 12531265 .

Diener, E./Sandvik, E./Pavot, W. G. (1991b): Happiness is the frequency, not the intensity, of positive versus negative affect. In: F. Stack, M. Argyle/N. Schwarz (Eds.): Subjective well-being: An interdisciplinary perspective. New York: Pergamon Press: 119-139.

Domeyko, M. (1996): Absolute happiness: The way to a life of complete fulfilment. Alexandria, New South Wales: Hay House.

Emmons, R. A./Diener, E. (1985): Personality correlates of subjective well-being. In: Personality and Social Psychology, 11: 89-97.

Erikson, E. (1959): Identity and the life cycle. In: Psychological Issues, 1: 18-164.

Evans, P. (1986): The strategic outcomes of human resource management. In: Human Resource Management, 25(1): 146-167.

Faragher, E. B./Cass, M./Cooper, C. L. (2005): The relationship between job satisfaction and health: a meta-analysis. In: Occupational and Environmental Medicine, 62: 105-112.

Feldman Barrett, L./Russell, J. A. (1998): Independence and bipolarity in the structure of affect. In: Journal of Personality and Social Psychology, 74(4): 967-984.

Fletcher, B. (1991): Work, stress, disease and life expectancy. New York: Wiley.

Ganster, D. C. (1989): Worker control and well-being: A review of research in the workplace. In: S. L. Sauter, J. J. Hurrell/C. L. Cooper (Eds.): Job control and worker health (pp.). New York: Wiley: 323.

Gardner, D. G./Cummings, L. L. (1988): Activation theory and job design: Review and reconceptualization. In: Research in Organizational Behavior, 10: 81-122.

George, J. M. (1992): The role of personality in organizational life: Issues and evidence. In: Journal of Management, 2: 85-213.

George, J. M./Brief, A. P. (1996): Motivational agendas in the workplace: The effects of feelings on focus of attention and work motivation. In: Research in Organizational Behavior, 18: 75-109. 
Goleman, D. (1998): What makes a leader? In: Harvard Business Review, 76(November- December): 93115.

Goleman, D. (1999): Working with emotional intelligence. London, United Kingdom: Bantam Books.

Hackman, J. R./Oldham, G. R. (1975): Development of the job diagnostic survey. In: Journal of Applied Psychology, 60: 159-170.

Hall, D. T. (1995): Executive careers and learning: Aligning selection, strategy and development. In: Human Resource Planning, 18(2): 14-23.

Harter, J. K./Schmidt, F. L./Keyes, C. L. M. (2002): Well-being in the workplace and its relationship to business outcomes: A review of the Gallup Studies. In: C. L. M. Keyes/J. Haidt (Eds.), Flourishing: The positive person and the good life. Washington, D.C: American Psychological Association: 205224.

Haslam, N. (1995a): The discreteness of emotion concepts: Categorical structure in the affective circumplex. In: Personality and Social Psychology Bulletin, 21: 1012-1019.

Haslam, N. (1995b): Four grammars for primate social relations. In: J. Simpson/D. Kenrick (Eds.): Evolutionary social psychology: Lawrence Erlbaum, in press.

Haybron, D. M. (2003): What do we want from a theory of happiness? In: Metaphilosophy, 34(3): 305329.

HayGroup (1999): What makes great leaders: Rethinking the route to effective leadership: Findings from Fortune Magazine/Hay Group 1999 Executive Survey of Leadership Effectiveness. Retrieved December 1. 2004, from

http:// ei.haygroup.com/downloads/pdf/Leadership\%20White\%20Paper.pdf.

Heller, W./Nitschke, J. B. (1998): The puzzle of regional brain activity in depression and anxiety: The importance of subtypes and comorbidity. In: Cognition and Emotion, 12: 421-447.

Hoppock, R. (1935): Job satisfaction. New York: Harper.

Hosie, P. (1994): The mental health implications of work. In: Singapore Management Review, 16(11): 4968.

Hosie, P./J./Sevastos, P./P./Cooper, C./L. (2006): Happy-Performing Managers: The Impact of Affective Wellbeing and Intrinsic Job Satisfaction in the Workplace. Cheltenham, UK, Northhampton, MA, USA: Edgar Elgar.

Hosie, P./Sevastos, P. (2007): Australian managers and the 'happy-performing managers' proposition. In: Journal of Human Values, 13(2): 151-176.

Hurrell, J. J./McLaney, M. A. (1989): Control, job demands, and job satisfaction. In: S. L. Sauter, J. J. Hurrell/C. L. Cooper (Eds.): Job control and worker health. Chichester, United Kingdom: Wiley: 97-103.

Hutchins, R. M. (Ed.). (1952): Pascal's 'the provincial letters,' 'pensees,' and 'scientific treatises' (Vol. 34). Chicago, Illinois: Britannica Inc.

Iaffaldano, M. T./Muchinsky, P. M. (1985): Job satisfaction and job performance: A meta-analysis. In: Psychological Bulletin, 97(2): 251-273.

Ilies, R./Judge, T. A. (2003): On the heritability of job satisfaction: The mediating role of personality. In: Journal of Applied Psychology, 88: 750-759.

Iverson, R. D./Erwin, P. J. (1997): Predicting occupational injury: The role of affectivity. In: Journal of Occupational and Organizational Psychology, 70(2): 113-128.

Johnson, J. V. (1991): Collective control: Strategies for survival in the workplace. In: J. V. Johnson/G. Johansson (Eds.): The psychosocial work environment: Work organizations, democratization and health. Baywood, New York: 121-132.

Judge, T. A. (1993): Does affective disposition moderate the relationship between job satisfaction and voluntary turnover? Journal of Applied Psychology, 78(3): 395-401.

Judge, T. A./Locke, E. A./Durham, C. C./Kluger, A. N. (1998): Dispositional effects on job and life satisfaction: The role of core evaluations. In: Journal of Applied Psychology, 83: 17-34.

Judge, T. A./Thoresen, C. J./Bono, J. E./Patton, G. K. (2001): The job satisfaction-job performance relationship: A qualitative and quantitative review. In: Psychological Bulletin, 127(3): 376-407.

Jung, C. G. (1933): Modern man in search of a soul. London, United Kingdom: Routledge/Kegan. 
Kanner, A. D./Coyne, J. C./Schaefer, C./Lazarus, R. S. (1981): Comparison of two models of stress management: Daily hassles and uplifts versus major life events. In: Journal of Behavioral Medicine, 4: 1-39.

Karasek, R. A. (1979): Job demands, job decision latitude, and mental strain: Implications for job redesign. In: Administrative Science Quarterly, 24(2): 285-308.

Karasek, R. A./Theorell, T. (1990): Healthy work: Stress reconstruction of working life. New York: Basic Books.

Kasl, S. V. (1989): An epidemiological perspective on the role of control in health. In: S. L. Sauter, J. J. Hurrell/C. L. Cooper (Eds.): Job control and worker health. Chichester, New York: Wiley: 161-190.

Kauppinen-Toropainen, K./Kandolin, I./Mutamen, P. (1983): Job dissatisfaction and work related exhaustion in male and female workers. In: Journal of Occupational Behaviour, 4: 193-207.

Kelloway, K. E./Barling, J. (1991): Job characteristics, role stress and mental health. In: Journal of Occupational Psychology, 64: 291-304.

Landsbergis, P. A. (1988): Occupational stress among health care workers: A test of the job demandscontrol model. In: Journal of Organizational Behavior, 9(3): 217-239.

Landy, F. J. (2005): Some historical and scientific issues related to research on emotional intelligence. In: Journal of Organizational Behavior, 26(4): 411-424.

Larsen, R. J./Ketelaar, T. (1989): Extraversion, neuroticism and susceptibility to positive and negative mood induction procedures. In: Personality and Individual Differences, 10(12): 1221-1228.

Ledford, G. E./Jr. (1999): Happiness and productivity revisited. In: Journal of Organizational Behavior, 20(1): 31-34.

Lewinsohn, P. M./Amenson, C. S. (1978): Some relations between pleasant and unpleasant events and depression. In: Journal of Abnormal Psychology, 87(6): 644-654.

Mackay, C. J./Cox, T./Burrows, G. C./Lazzarini, A. J. (1978): An inventory for the measurement of selfreported stress and arousal. In: British Journal of Social and Clinical Psychology, 17(3): 283-284.

Maslow, A. H. (1968): Towards a psychology of being (2nd ed.). New York: Van Nostrand.

Mayer, J./Caruso, D. R./Salovey, P. (2000): Selecting a measure of emotional intelligence: The case for ability scales. In: R. R. Bar-On/J. D. A. Parker (Eds.): The handbook of emotional intelligence . San Francisco: Jossey-Bass: 320-342.

McDougal, W. (1905): Physiological psychology. London, United Kingdom: Aldine House.

Meyer, G. J./Shack, J. R. (1989): Structural convergence of mood and personality: Evidence for old and new directions. In: Journal of Personality and Social Psychology, 57(4): 691-706.

Meyer, J. P./Paunonen, S. V./Gellatly, I. R./Goffin, R. D./Jackson, D. N. (1989): Organizational commitment and job performance: It's the nature of the commitment that counts. In: Journal of Applied Psychology, 74(1): 152-156.

Münsterberg, H. (1913): Psychology and Industrial Efficiency: Houghton Mifflin Company, The Riverside Press Cambridge.

Nankervis, A./Compton, R./McCarthy, T. (1996): Strategic Human Resource Management. Victoria: Thomson.

Organ, D. W./Near, J. P. (1985): Cognitions vs affect in measures of job satisfaction. In: International Journal of Psychology, 20: 241-253.

Oshagbemi, T. (1991): Overall job satisfaction: How good are single vs. multiple item measures? In: Journal of Managerial Psychology, 14: 388-403.

Parkes, K. R. (1990): Coping, negative affectivity and the work environment: Additive and interactive predictors of mental health. In: Journal of Applied Psychology, 75(4): 399-409.

Parkes, K. R. (1991): Locus of control as moderator: An explanation for additive versus interactive findings in the demand-discretion model for work stress. In: British Journal of Psychology, 82(3): 291312.

Parkes, K. R./Mendham, C. A./Von Rabenau, C. (1994): Social support and the demand-discretion model of job stress: Tests of additive and interactive effects in two samples. In: Journal of Vocational Behavior, 44(1): 99-113.

Payne, R. L./Fletcher, B. (1983): Job demands, supports and constraints as predictors of psychological strain among schoolteachers. In: Journal of Vocational Behavior, 22(2): 136-147. 
Rogers, C. R. (1961): On becoming a person. Boston, Massachusetts: Houghton Mifflin.

Ross, P. (1989): Work, unemployment and mental health. In: Journal of Occupational Psychology, 87.

Russell, J. A. (1980): A circumplex model of affect. In: Journal of Personality and Social Psychology, 39: 1161-1178.

Russell, J. A./Feldman Barrett, L. (1999): Core affect, prototypical emotional episodes, and other things called emotion: Dissecting the elephant. In: Journal of Personality and Social Psychology, 76: 805819.

Ryff, C. D./Keyes, C. L. M. (1995): The structure of psychological well-being revisited. In: Journal of Personality and Social Psychology, 69(4): 719-727.

Schaubroeck, J./Ganster, D. C./Fox, M. L. (1992): Dispositional affect and work-related stress. In: Journal of Applied Psychology, 77(3): 322-335.

Schimmack, U. (2001): Please, displeasure, and mixed feelings: Are semantic opposites mutually exclusive? In: Cognition and Emotion, 15(1): 81-97.

Selye, H. (1974): The stress of life. New York: McGraw-Hill.

Sevastos, P. P. (1996): Job-related affective well-being and its relation to intrinsic job satisfaction. Unpublished PhD Thesis. Curtin University.

Spector, P. E. (1987): Method variance as an artifact in self-reported affect and perceptions at work: Myth or significant problem?. In: Journal of Applied Psychology, 72(3): 438-443.

Stacey, C. A./Gatz, M. (1991): Cross-sectional age differences and longitudinal change on the Bradburn affect-balance scale. In: Journal of Gerontology, 46(2): 76-78.

Staw, B. M. (1986): Organizational psychology and the pursuit of the happy/productive worker. In: California Management Review, 28(4): 40-53.

Staw, B. M./Barsade, S. G. (1993): Affect and managerial performance: A test of the sadder-but-wiser vs. happier-and-smarter hypotheses. In: Administrative Science Quarterly, 38: 304-331.

Staw, B. M./Bell, N. E./Clausen, J. A. (1986): The dispositional approach to job attitudes: A lifetime longitudinal test. In: Administrative Science Quarterly, 31(1): 56-77.

Staw, B. M./Cohen-Charash, Y. (2005): The dispositional approach to job satisfaction: more than a mirage, but not yet an oasis. In: Journal of Organizational Behavior, 26: 59-78.

Staw, B. M./Ross, J. (1985): Stability in the midst of change: A dispositional approach to job attitudes. In: Journal of Applied Psychology, 70(3): 469-480.

Suh, E./Diener, E./Fujita, F. (1996): Events and subjective well-being: Only recent events matter. In: Journal of Personality and Social Psychology, 70: 1091-1102.

Sweeney, P. D./Schaeffer, D. E./Golin, S. (1982): Pleasant events, unpleasant events, and depression. In: Journal of Personality and Social Psychology, 43(1): 136-144.

Tellegen, A. (1985): Structures of mood and personality and their relevance to assessing anxiety with an emphasis on self-report. In: A. H. Tuma/J. Maser (Eds.): Anxiety and the anxiety disorders. Hillsdale, New Jersey: Erlbaum: 681-706.

Thayer, R. E. (1978): Towards a theory of multidimensional activation (arousal). In: Motivation and Emotion, 2: 1-33.

Tracey, B. (1993): Maximum Achievement. New York: Simon/Schuster.

Tucker, D. M./Williamson, P. A. (1984): Asymmetric neural control systems of human self-regulation. In: Psychological Review, 91(2): 185-215.

Veenhoven, R. (1995a): Developments in satisfaction research. In: Social Indicators Research, 37: 1-46.

Veenhoven, R. (1995b): World database of happiness. In: Social Indicators Research, 34: 299-313.

Warr, P. B. (1986): A vitamin model of jobs and mental health. In: H. W. Debus/H. W. Schroiff (Eds.): The psychology of work and organisation: Current trends and issues. Amsterdam, Holland: Elsevier Science: $157-164$.

Warr, P. B. (1987): Work, unemployment and mental health. Oxford, United Kingdom: Clarendon Press.

Warr, P. B. (1990a): Decision latitude job demands and employee well-being. In: Work/Stress, 4(4): 284294.

Warr, P. B. (1990b): The measurement of well-being and other aspects of mental health. In: Journal of Occupational Psychology, 63(3): 193-210.

Warr, P. B. (1992): Age and occupational well-being. In: Psychology and Aging, 7(1): 37-45. 
Warr, P. B. (1994a): Age and work. In: P. Collett,/A Furnham (Eds.): Social psychology at work. London: Routledge: 236-253.

Warr, P. B. (1994b): Aging and employment: Palo Alto, CA: Consulting Psychologists Press.

Warr, P. B. (1994c): A conceptual framework for the study of work and mental health: A healthier work environment. In: Work \& Stress, 8(2): 84-97.

Warr, P. B. (2007): Work, Happiness, and Unhappiness. Mahwah, New Jersey, USA: Lawrence Erlbaum Associates.

Warr, P. B. (Ed.) (1996): Psychology at work (4th ed.). London, United Kingdom: Penguin.

Warr, P. B./Barter, J./Brownbridge, G. (1983): On the independence of positive and negative affect. In: Journal of Personality and Social Psychology, 44: 644-651.

Warr, P. B./Cook, J./Wall, T. D. (1979): Scales for the measurement of some work attitudes and aspects of psychological well-being. In: Journal of Occupational Psychology, 52: 129-148.

Waterfield, R. (1993): Letter on happiness. London, United Kingdom: Elbury Press.

Watson, D. (1988): Intra-individual and inter-individual analyses of positive and negative affect: Their relation to health complaints, perceived stress and daily activities. In: Journal of Personality and Social Psychology, 54: 1020-1030.

Watson, D./Clark, L. A. (1984): Negative affectivity: The disposition to experience aversive emotional states. In: Psychological Bulletin, 96(3): 465-490.

Watson, D./Clark, L. A./Carey, G. (1988): Positive and negative affectivity and their relation to anxiety and depressive disorders. In: Journal of Abnormal Psychology, 97(3): 346-353.

Watson, D./Pennebaker, J. W. (1989): Health complaints, stress, and distress: Exploring the central role of negative affectivity. In: Psychological Review, 96(2): 234-254.

Watson, D./Pennebaker, J. W./Folger, R. (1987): Beyond negative affectivity: Measuring stress and satisfaction in the workplace. In: J. M. Ivancevich/D. C. Ganster (Eds.): Job stress: From theory to suggestion. New York: Haworth Press: 141-157.

Watson, D./Tellegen, A. (1985): Towards a consensual structure of mood. Psychological Bulletin, 98(2): 219-235.

Weiss, H. M./Cropanzano, R. (1996): Affective events theory: A theoretical discussion of the structure, causes and consequences of affective experiences at work. In: B. M. Staw/L. L. Cummings (Eds.): Research in organizational behavior: An annual series of analytical essays and critical reviews, 18: 174. Greenwich, CT: JAI Press, Inc.

Williams, L. G./Podsakoff, P. M. (1989): Longitudinal field methods for studying reciprocal relationships in organizational behavior research: Toward improved causal analysis. In: Research in Organizational Behavior, 11: 247-292.

Wright, T. A./Cropanzano, R./S. (1997): Well-being, satisfaction and job performance: another look at the happy/productive worker thesis. In: Academy of Management Proceedings: 364-371.

Wright, T. A./Cropanzano, R./S. (2000): Psychological well-being and job satisfaction as predictors of job performance. In: Journal of Occupational and Health Psychology, 5(1): 84-94.

Wright, T. A./Cropanzano, R./S./Denney, P. J./Moline, G. L. (2002): When a happy worker is a productive worker: A preliminary examination of three models. In: Canadian Journal of Behavioural Science, 34(3): 146-150.

Wright, T. A./Staw, B./M. (1999b): Further thoughts on the happy-productive worker. In: Journal of Organizational Behavior, 20(1): 31-34.

Wright, T. A./Staw, B. M. (1999a): Affect and favorable work outcomes: Two longitudinal tests of the happy-productive worker thesis. In: Journal of Organizational Behavior, 20(1): 1-23. 